\section{British council under new threat}

THE least favoured of the British research councils, the Agricultural and Food Research Council (AFRC), is faced with yet another period of contraction. At the end of a year in which it has shed 550 jobs, onesixth of the total, the council is now faced with the prospect of a further reduction of research commissioned by the three agriculture ministries, the Ministry of Agriculture, Fisheries and Food and the ministries for Scotland and Northern Ireland.

This is the gloomy theme of the second of the council's corporate plans, published earlier this week. Sir Ralph Riley, the secretary of the council who retires on 1 April, says in his preface to this document, which will become the basis of the council's claim on public funds in the financial year beginning in April 1986, that a revised plan may be necessary when the government's intentions are known.

The discontent of successive British governments with the council's work goes back at least to an internal inquiry in the late 1960s. At the time of the Rothschild reorganization in 1972-73, AFRC was the most directly affected, being required to depend on commissioned research from the

\section{Schopper to stay}

THE European Organization for Nuclear Research (CERN), near Geneva is to be directed for a further four years by the present incumbent, Professor Herwig Schopper of West Germany. He will thus remain director-general until the end of 1988 , which should see the end of the large electron-positron collider (LEP) project.

Italy, which had been campaigning for a strong place in the directorate, has won a place for Professor Carlo Rubbia, Nobellist for his discovery of $W$ and $Z$ particles with his CERN proton-antiproton collider. Rubbia will chair a working group which will study "the long-range scientific and technological future" of CERN.

Meanwhile, after a meeting on the latest proton-antiproton collider results in St Vincent, in northern Italy, last week, physicists were surprised by the continuing discovery of events producing pairs of muons each carrying the same electric charge, but moving in opposite directions. A total of seven such events have now been seen in which the muons are not associated with "jets", the now-familiar signal for quark production and decay. Four of the events have no jets at all, and in five of the seven, strange quarks are produced (double the expected rate). No satisfactory explanation for these "like-sign dimuons" has been offered. Rubbia described these results and others as "a lot of good things cooking". However, "we must be prudent" in their interpretation.

Robert Walgate agriculture departments for 75 per cent of its budget. In the past decade, the volume of commissioned work has steadily declined, as has the council's share of the science budget (from which all research council formally dissented from the annual allocation recommended by the Advisory Board for the Research Councils (ABRC).

In the financial year now ending, AFRC and the Scottish institutes will have received $£ 46.7$ million from the science budget and the remainder of the total of $\$ 121.6$ million by way of commissions. The planned increase of the cash budget for 1984-85 to f125.6 million (not fully compensating for inflation) includes an increase of $£ 3.6$ million from the science budget and of $£ 0.5$ million in commissioned research.

Government forecasts of public spending published last December show the total budget standing at $£ 126.8$ million three years from now (in 1987-88), but the corporate plan says that even this static budget has now been put in doubt by the planned reductions of departmental research and development of $\mathfrak{1 1 0}$ million in 1986-87 and of $£ 20$ million in 1987-88.

The council is particularly sore at the way in which a Cabinet Office paper published at the end of last year used a comparison of agricultural research costs and output values in the countries of the Organisation for Economic Cooperation and Development (OECD) to demonstrate that Britain spends a greater proportion of the value of agricultural output on research and development than other countries. The assertion was quickly denied (Nature 3 January, p.8), and the corporate plan published this week says that other indicators would lead to different comparisons. Yet senior of ficials of the council fear that the Cabinet Office comparison is still being "hawked around Whitehall" to try to discredit its programme of research.

For the rest, AFRC seems not to have won the moral support it might have expected from the newly-formed Priorities Board on Research and Development in Agriculture and Food, which has apparently been asked to consider what steps could be taken to increase industrial sponsorship for the council's research. The board has apparently taken the line that the central government should pay only for what others cannot be expected to pay for.

The corporate plan says that if the council's budget is further reduced, "further restructuring" may be necessary. During the past few years, this has chiefly meant the closing of research stations and the shedding of staff, but now there is also talk of allowing some parts of the agricultural research enterprise to become freestanding. The possibility that there may be a merger of AFRC and the Scottish research stations is also being explored. councils are supported). Two years ago, the

\section{Planned contraction}

THE chief ingredients of the new corporate plan for agricultural research, covering both the work of AFRC and the Scottish stations supported directly by the Department of Agriculture and Fisheries for Scotland are as follows:

University research. The plan is that spending on research grants (increased by 8.5 per cent to $£ 5.4$ million this financial year) should continue to take a larger share of total funds. By 1989-90, the plan says, $£ 7$ million a year will be spent in this way, with priority given to food research.

Food science. The plan says that AFRC has warmly endorsed the recommendations of the Advisory Council for Applied Research and Development (ACARD) in 1983 that more attention should be paid to food science. Research spending will increase from $£ 13.3$ million this year to $£ 19.3$ million five years from now, or by 26 per cent in real terms. The plan is to concentrate this work on the three research stations at Bristol, Norwich and Reading, but other council research institutes will also be involved.

Animals research. The intention is that spending on animal diseases should decrease by 16 per cent (to a cash value of £16.4 million a year) over the next five years. Part of the council's recent restructuring has entailed the merging of the Grasslands Research Institute and the National Institute for Research in Dairying at a new site at Hurley, in Berkshire. During the coming year, the Animals Research Institute at Cambridge will be merged with its parent station at nearby Babraham.

Forage crops. The corporate plan outlines a strategy on concentration of research under the umbrella of the Animals and Grasslands Research Institute, with the Welsh Plant Breeding Research Institute and its two Scottish equivalents taking more tightly defined roles within the whole. Plant protection research will decline in the next five years by 16 per cent.

Capital development. The plan says that the recent tendency to spend 12 per cent of the AFRC budget on buildings "cannot be sustained", and that it will in future not be possible to replace some obsolete equipment or even to provide the material support for some new research programmes. But the council plans to earmark $£ 3.5$ million from the budget for the year after next to support initiatives not yet proposed. Manpower. In the year now ending, 100 of the 550 posts lost from the AFRC establishment have been compulsorily vacated. The earlier contraction of AFRC, not yet completed, entails the loss of a further 250 posts during the coming year; the new plan says that it will also be necessary to lose a further 800 posts in the next two years, offset by an increase of 60 posts for food research. The rule that people should retire at age 60 will be strictly enforced, and as many as possible of those not needed will be persuaded to take early retirement. $\square$ 